\title{
The clinical potential of influencing Nrf2 signaling in degenerative and immunological disorders
}

This article was published in the following Dove Press journal:

Clinical Pharmacology:Advances and Applications

3 February 2014

Number of times this article has been viewed

\section{Bifeng Gao \\ An Doan \\ Brooks M Hybertson}

Department of Medicine, Division of Pulmonary Sciences and Critical Care Medicine, University of Colorado Anschutz Medical Campus, Aurora, CO, USA
Correspondence: Brooks M Hybertson Department of Medicine, Division of Pulmonary Sciences and Critical Care Medicine, Box C272, 12700 East 19th Avenue, University of Colorado Anschutz Medical Campus, Aurora, CO 80045, USA Email brooks.hybertson@ucdenver.edu
Abstract: Nuclear factor (erythroid-derived 2)-like 2 (Nrf2; encoded in humans by the NFE2L2 gene) is a transcription factor that regulates the gene expression of a wide variety of cytoprotective phase II detoxification and antioxidant enzymes through a promoter sequence known as the antioxidant-responsive element (ARE). The ARE is a promoter element found in many cytoprotective genes; therefore, Nrf2 plays a pivotal role in the ARE-driven cellular defense system against environmental stresses. Agents that target the ARE/Nrf2 pathway have been tested in a wide variety of disorders, with at least one new Nrf2-activating drug now approved by the US Food and Drug Administration. Examination of in vitro and in vivo experimental results, and taking into account recent human clinical trial results, has led to an opinion that Nrf2-activating strategies - which can include drugs, foods, dietary supplements, and exercise - are likely best targeted at disease prevention, disease recurrence prevention, or slowing of disease progression in early stage illnesses; they may also be useful as an interventional strategy. However, this rubric may be viewed even more conservatively in the pathophysiology of cancer. The activation of the Nrf2 pathway has been widely accepted as offering chemoprevention benefit, but it may be unhelpful or even harmful in the setting of established cancers. For example, Nrf2 activation might interfere with chemotherapies or radiotherapies or otherwise give tumor cells additional growth and survival advantages, unless they already possess mutations that fully activate their Nrf2 pathway constitutively. With all this in mind, the ARE/Nrf2 pathway remains of great interest as a possible target for the pharmacological control of degenerative and immunological diseases, both by activation and by inhibition, and its regulation remains a promising biological target for the development of new therapies.

Keywords: Nrf2, detoxification, antioxidant

\section{Introduction}

Nrf2 and ARE

Cells respond to oxidative stress or electrophilic xenobiotics mainly through the transcription factor Nrf2 (nuclear factor [erythroid-derived 2]-like 2). Nrf2 upregulates a series of phase II detoxification and antioxidant genes, ${ }^{1,2}$ as well as cell survival, antiinflammatory, energy metabolism, and other groups of genes that contain a cis-acting element in their promoter region recognized as the antioxidant response element (ARE) or electrophile response element (EpRE). Although there is some level of variability allowed in the specific nucleotide positions, the consensus sequence for the core ARE is generally identified as TGACnnnGC. ${ }^{3-7}$ The additional functional sequence content of the binding site is referred to as the extended ARE (TMAnnRTGAYnnnGCRwwww) which is proposed to define a more sufficient, functional ARE. ${ }^{7,8}$ 
Nrf2, sometimes referred to as the master regulator of antioxidant, detoxification, and cell defense gene expression, was initially identified and cloned 20 years ago. ${ }^{9}$ This discovery occurred just a few years after the initial reports of the ARE, ${ }^{4,10,11}$ and was coincident with identification of the chemicals that induce phase II enzymes through the ARE response. ${ }^{6,12,13}$ Prior to these discoveries, for years scientists had suspected the existence of oxidative stress-sensing mechanisms to explain corresponding gene regulation patterns. In fact, the upregulation of antioxidant and detoxification genes was noted for a variety of chemical inducers prior to the discovery and knowledge of the ARE, Nrf2, or Nrf2-regulating molecules.

\section{Nrf2 activation}

Under normal conditions, Nrf2 is bound in the cytoplasm to Keap1 (Kelch-Like ECH-Associated Protein 1, also known as an inhibitor of Nrf2, INrf2) and targeted for ubiquitination and proteasomal degradation. So called Nrf2 activators (oxidants, electrophiles, and other agents) stabilize Nrf2 to allow it to migrate to and accumulate in the nucleus. ${ }^{14,15}$ This typically occurs by reaction with cysteine thiols on Keap 1 and interference with its Nrf2 binding, thereby decreasing the ubiquitin E3 ligase activity of the overall Keap1 complex, ${ }^{16-19}$ and also possibly occur via kinase-dependent phosphorylation of Nrf2, although the relative contribution of kinases to Nrf2 activation has been suggested to be lower than the Keap1 sensor activity (Figure 1).20-23 Demonstration of the regulation of the Nrf2 pathway by phosphorylation of Nrf2 at serine and threonine residues through phosphatidylinositol 3-kinase (PI3K), c-Jun $\mathrm{N}$-terminal kinase (JNK), and extracellular signal-regulated protein kinase (ERK) creates opportunities for new approaches to controlling Nrf2 activation in future work. ${ }^{24}$

The mechanism of activation is potentially relevant to additional effects of Nrf2 activators and should be kept in mind during new drug development. For example, drug candidates that act as electrophiles and react with Keap1 thiol groups could act on other electrophile-sensitive pathways, such as histone deacetylase enzymes. ${ }^{25}$ Hundreds of genes contain the ARE in their regulatory promoter regions. ${ }^{26}$ Stabilized Nrf2 that migrates into the nucleus can form heterodimers with other proteins such as small Maf proteins, ${ }^{3,27}$

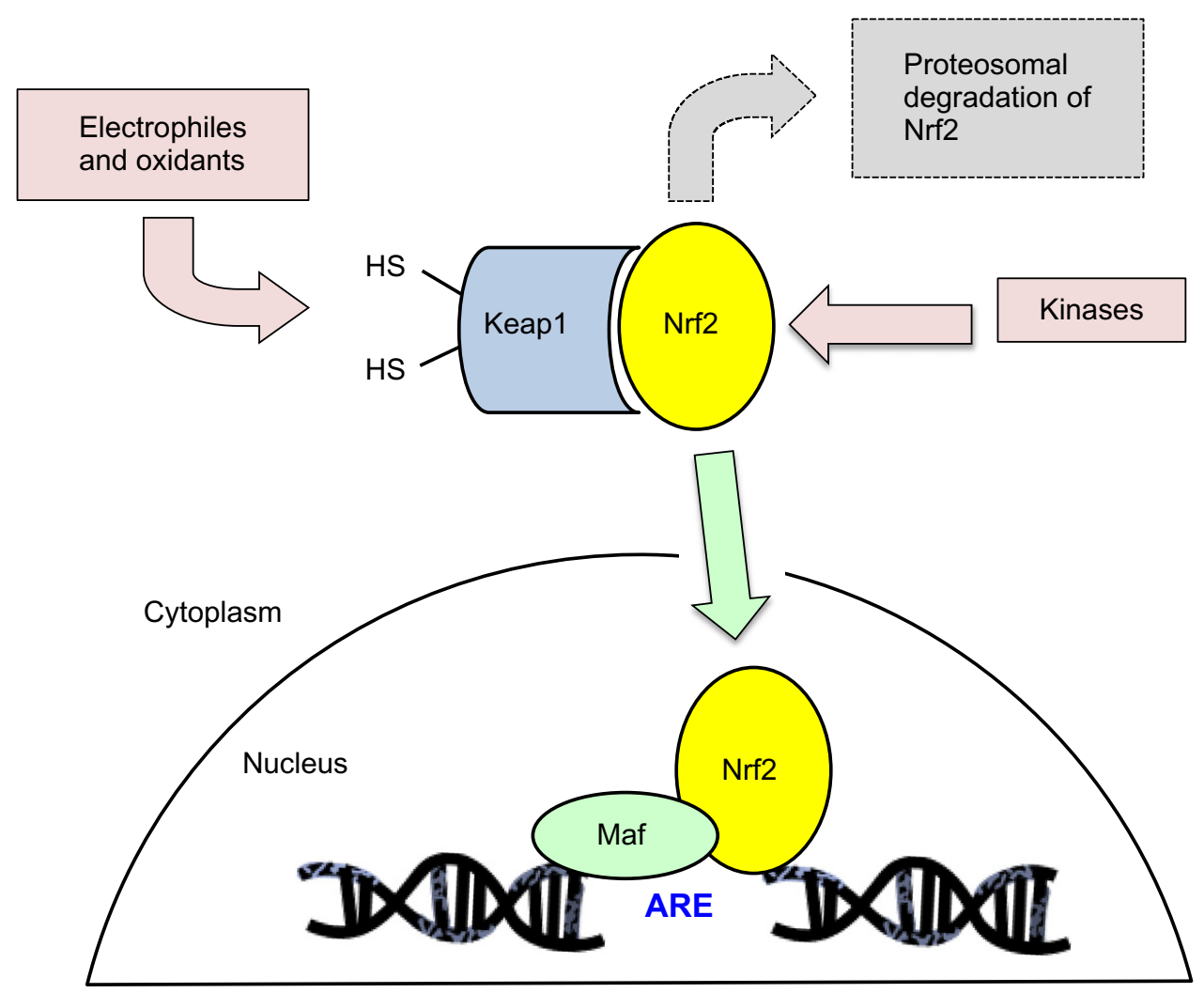

Figure I Schematic representation of the Nrf2/Keap I intracellular pathway.

Notes: Under normal conditions, Keapl binds Nrf2 in the cytoplasm and promotes both the Cullin-3 containing ubiquitin E3 ligase ubiquitination of Nrf2 and its targeting for degradation by the proteasome. When Nrf2 is stabilized through electrophiles, oxidants, or other agents that can interact with Keapl cysteine thiols, or by agents that increase kinase-dependent phosphorylation of Nrf2, it can accumulate in the nucleus, form heterodimers with small Maf proteins, and bind with the ARE of target genes. Abbreviations: Nrf2, nuclear factor (erythroid-derived 2)-like 2; ARE, antioxidant response element; KeapI, Kelch-Like ECH-Associated Protein I. 
and then bind to and interact with gene promoter ARE sequences and modulate gene transcription. This is usually discussed in terms of Nrf2-responsive gene upregulation, but some genes are downregulated following Nrf2 activation as well. Following translocation to the nucleus, Nrf2 repression has been demonstrated based on Keap1 import into the nucleus and either degradation of Nrf2 in the nucleus, ${ }^{28}$ or export of Nrf2 out of the nucleus and degradation in the cytosol, ${ }^{29}$ both of which constitute a means of turning off $\mathrm{Nrf} 2$ signaling and preventing permanent induction of Nrf2regulated genes.

Recently, Narasimhan et al documented the direct involvement of microribonucleic acids (miRNAs) to mediate posttranscriptional tuning of Nrf2 and its associated redox homeostasis mechanism. ${ }^{30}$ In another study, Cheng et $\mathrm{al}^{31}$ have highlighted how Nrf2 can be regulated indirectly by miRNAs via control of redox signaling. It has also been shown that a closely related family member (Nrf1) can also engage the ARE and either compete with or inhibit Nrf2 from activating ARE-dependent gene transcription. ${ }^{32,33}$

Nrf2 has established functions in endo/xenobiotic detoxification, antioxidants, and antiinflammatory response. Based on numerous biochemical studies and global gene expression profiling, ${ }^{26,34-36}$ it is now evident that both the Keap1-dependent and Keap1-independent Nrf2 pathways control the gene expression of a battery of cytoprotective and detoxifying enzymes and play a vital role in maintaining redox cellular homeostasis. ${ }^{37-39} \mathrm{~A}$ substantial literature documents that an imbalance of cellular redox status contributes to the pathogenesis of degenerative and immunological disorders. Thus, Nrf2 activation or inhibition responding to cellular oxidative and electrophilic stress, and designed to restore redox homeostasis, paves a new way to understand, prevent, or even cure these complex diseases.

In the present work, Nrf2 transcription factor (NFE2L2) binding sites were identified in the 25 genes with the highest fold-induction from our previous phytochemical Nrf2 activation study using Protandim ${ }^{\circledR}$ (LifeVantage, Inc., Sandy, UT, USA; a mixture of extracts of milk thistle, bacopa, ashwagandha, green tea, and turmeric $)^{40}$ and used to generate a sequence logo using Weblogo 3 (http://weblogo.threeplusone. com/)..$^{41,42}$ The ARE motif sequence logo generated from the upregulated genes in our prior study is shown in Figure 2; however, while it is only based on sequence information and not bona fide Nrf2 binding studies, it allows for comparisons against the consensus ARE and chromatin-immunoprecipitation (ChIP)-verified Nrf2 binding sequences. It depicts,

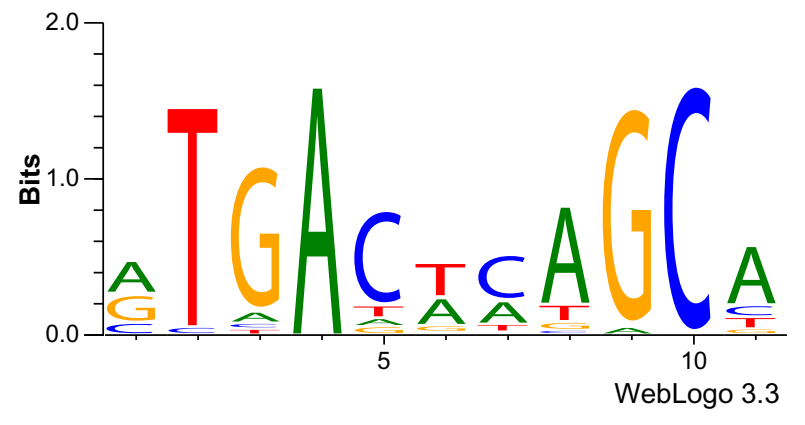

Figure 2 Typical ARE sequence logo. An ARE sequence logo was generated using predicted Nrf2 binding sites in the regulatory regions of the highest upregulated genes from Hybertson et $\mathrm{al}^{40}{ }^{40}$ in which cultured human umbilical vein endothelial cells were treated with a phytochemical Nrf2 activator mixture.

Notes: Using oPOSSUM 3.0 web-based software (http://opossum.cisreg.cal oPOSSUM3/) we evaluated Nrf2 binding sites in the 25 genes with the highest fold-induction from our previous phytochemical Nrf2 activation study using Protandim ${ }^{\circledR}$ (LifeVantage, Inc., Sandy, UT, USA; a mixture of extracts of milk thistle, bacopa, ashwagandha, green tea, and turmeric), ${ }^{40}$ examining 10,000 bases upstream and 5,000 bases downstream of the transcription start site and aligning potential Nrf2 binding sites. ${ }^{43,44}$ Thirty one Nrf2 binding sites were identified in 14 of the 25 genes that were upregulated by the $\mathrm{Nrf2}$ activator. ${ }^{40}$

Abbreviations: Nrf2, nuclear factor (erythroid-derived 2)-like 2; ARE, antioxidant response element.

as expected, a match between the gene data and the corresponding bases from the central part of the extended ARE $($ RTGAYnnnGCR $),{ }^{7,8}$ where $\mathrm{R}=\mathrm{A}$ or $\mathrm{G}$, and $\mathrm{Y}=\mathrm{C}$ or $\mathrm{T}$.

\section{Review of genes and results for degenerative and immunological disorders pertaining to Nrf2 Nrf2 target genes}

Thimmulappa et al investigated Nrf2-regulated genes induced by the chemopreventive agent sulforaphane using oligonucleotide microarray. ${ }^{34}$ In the study, a transcriptional profile of the small intestine of wild-type ( $n r f 2+/+)$ and knock out (nrf2-l-) mice treated with vehicle or sulforaphane was generated. Seventy seven Nrf2-upregulated genes were identified, including $N A D(P) H:$ :quinone reductase (NQO1), glutathione $S$-transferase (GST), $\gamma$-glutamylcysteine synthetase, uridine diphosphate-glucuronosyltransferases, and epoxide hydrolase. Also identified were genes encoding for cellular nicotinamide adenine dinucleotide phosphate (NADPH)-regenerating enzymes, including the following: glucose 6-phosphate dehydrogenase, 6-phosphogluconate dehydrogenase, and malic enzyme; various xenobiotic metabolizing enzymes; antioxidants such as glutathione peroxidase, glutathione reductase, ferritin, and haptaglobin; and biosynthetic enzymes of the glutathione and glucuronidation conjugation pathways.

To identify direct targets of Nrf2, Malhotra et al used mouse embryonic fibroblasts with either constitutive nuclear 
accumulation (Keap1-/-) or depletion (Nrf2-/-) of $\mathrm{Nrf} 2$ to perform ChIP with parallel sequencing (ChIP-Seq) and microarray profiling. ${ }^{45}$ Integrating ChIP-Seq and microarray analyses, 645 basal and 654 inducible direct targets of Nrf2 were identified, with 244 genes at the intersection. Further gene ontology (GO) analysis revealed that 'cell proliferation' dominates the basal gene set and 'response to oxidative stress' genes are the most prominent in the inducible gene set. Recently, Chorley et al conducted ChIP-sequencing experiments in lymphoid cells treated with the dietary isothiocyanate (sulforaphane) and carried out follow-up biological experiments on candidates. ${ }^{26}$ They found 242 high confidence, Nrf2-bound genomic regions; $96 \%$ of these regions contained Nrf2-regulatory sequence motifs. A microarray gene expression study revealed that 508 genes changed by 1.3 -fold or greater, with 70 of them having both ChIP-Seq peaks and gene expression changes. Hirotsu et al used the ChIP-Seq approach to identify binding sites of Nrf2 and MafG throughout the genome. They found a correlation with ARE motifs that was not seen in Nrf2-binding sites that did not also bind MafG. They also observed that Nrf2-MafG target genes included genes involved in cytoprotective and metabolic functions. ${ }^{3}$

It is, of course, important to note that the specific conditions such as sampling protocol, Nrf2 activation approaches (eg, chemical or genetic), potency of $\mathrm{Nrf} 2$ activators utilized, and cell/tissue types studied are all critical to monitoring the transcriptional activation of any gene. That is, the different experimental conditions and different antibodies used in unique assays may result in identification of different Nrf2dependent gene profiles, although cytoprotective genes are mostly observed. A comprehensive description of all Nrf2regulated genes is beyond the scope of this review, though here we do include some example genes and their products.

The NQO1 (NAD(P)H Dehydrogenase, Quinone 1) gene is one of the most robust responders to both chemical and genetic activation of Nrf2 ${ }^{46,47}$ This gene is a member of the $\mathrm{NAD}(\mathrm{P}) \mathrm{H}$ dehydrogenase (quinone) family and encodes a cytoplasmic 2-electron reductase which reduces quinones to hydroquinones. Lower NQO1 activity caused by gene mutations has been associated with tardive dyskinesia, ${ }^{48}$ an increased pulmonary susceptibility to ozone, ${ }^{49}$ and susceptibility to various forms of cancer. ${ }^{50,51}$ In addition, NQO1 binds and protects the tumor suppressor p53 against proteasomal degradation; thus, it has even broader cytoprotective roles, beyond its enzymatic functions. ${ }^{52}$

The aldo-keto reductases (AKRs) are some of the most inducible Nrf2 target genes in human cells and tissues. ${ }^{53}$
The AKR superfamily comprises enzymes that catalyze the NADPH-dependent reduction of a wide variety of carbonyl compounds such as glucose, steroids, glycosylation endproducts, and lipid peroxidation products, as well as xenobiotic aldehydes and ketones. ${ }^{54}$ Working together, the AKRs get the carbonyl group ready for consequent conjugation, for instance, glucuronidation and sulfation, and eventually for excretion. As a result, AKRs play an important role in the phase II detoxification of a large number of pharmaceuticals, drugs, and xenobiotics.

Heme oxygenase-1 (HO-1) is an enzyme that catalyzes the degradation of heme. This reaction generates carbon monoxide, biliverdin, and free iron which are responsible for much of the biologic activity of HO-1, including antiinflammatory and antioxidant effects. ${ }^{55-57} \mathrm{Nrf} 2$ participates in the regulation of the gene expression of $\mathrm{HO}-1$, which in concert with bilirubin reductase generate the antioxidants carbon monoxide and bilirubin. ${ }^{58}$ The upstream regulatory regions of the gene-encoding heme oxygenase 1 contain multiple AREs, which are responsible for its robust inducibility by various small-molecule Nrf2 activators. ${ }^{6}$

Glutathione reductase is another Nrf2-regulated enzyme which plays a critical role in maintaining cells' reducing environment and in battling oxidative stress. ${ }^{59,60}$ Furthermore, transcription of SLC7A11 (solute carrier family 7 [anionic amino acid transporter light chain, xc-system], member 11, also known as $\mathrm{xCT}$ ) is regulated by Nrf2 and plays an important role in cellular cystine-glutamate exchange, thereby contributing to regulation of glutathione synthesis and intracellular glutathione levels. ${ }^{61-63}$

\section{Degenerative and immunological disorders}

Degenerative and immunological disorders - examples of which include atherosclerosis, inflammatory bowel disease (IBD), diabetes, rheumatoid arthritis, human immunodeficiency virus/acquired immunodeficiency syndrome (HIV/ AIDS), neurological disorders, sepsis, cancer, and many others - affect more than 45 million people worldwide. Though the illnesses are very different, the Nrf2 pathway plays a role in many of them.

\section{Atherosclerosis}

Atherosclerosis is a disorder of the arterial vasculature marked by inflammation and plaque formation. Collins et al have found that myeloid-derived Nrf2 activity attenuates atherosclerosis development, liver inflammation, and fibrosis associated with obesity in an obese hypercholesterolemic mouse model. ${ }^{64}$ 
Similarly, in low-density lipoprotein receptor-deficient mice, Ruotsalainen et al found that Nrf2 deficiency specific to bone marrow-derived cells aggravates atherosclerosis, and that Nrf2 deficiency in macrophages promotes inflammation and foam cell formation. ${ }^{65}$ Prior research in our laboratory using primary human umbilical vein endothelial cells revealed that 19 genes that have been associated with atherosclerosis in the literature were up or downregulated by treatment with a phytochemical mixture Nrf2 activator; ${ }^{40}$ we also found that 16 of them (84\%) were regulated by Nrf2 activation in the opposing direction to that taken by the atherosclerosis disease process. ${ }^{40}$ On the other hand, Barajas et al found that in apolipoprotein E-deficient (Apoe [-/-]) male mice, knocking out Nrf2 decreases aortic atherosclerosis. ${ }^{66,67}$ Combined, the work suggests the need to consider roles for both Nrf2 activators and Nrf2 inhibitors in future atherosclerosis research.

\section{IBD}

IBD is a group of chronic inflammatory disorders of the intestine. Khor et al investigated the role of Nrf2 in the regulation of dextran sulfate sodium-induced experimental colitis in mice and concluded that Nrf2 contributed to intestinal protection through regulation of proinflammatory cytokines and induction of phase II detoxifying enzymes. ${ }^{68}$ Arisawa et al found that a Nrf2 gene polymorphism that reduces the activity of Nrf2 was associated with increased risk of IBD ulcerative colitis in a Japanese study population. ${ }^{69}$ Because inflammation and oxidative stress feature prominently in IBD,${ }^{70}$ studies of the potential benefits of Nrf2 activation and relevant drug development are warranted.

\section{Type I diabetes}

Type I diabetes is a disorder of the human immune system in which the patient's pancreas produces little or no insulin. In promising cell culture work, Nrf2 overexpression made model $\beta$-cells resistant to nitric oxide-induced apoptosis. ${ }^{71}$ In a study of the link between oxidative stress and insulin resistance in cardiac cells, Tan et al found that ERK-mediated suppression of Nrf2 activity leads to the oxidative stress-induced insulin resistance in adult cardiomyocytes and downregulated glucose utilization in the diabetic heart. ${ }^{72}$ Zheng et al induced diabetes in $\mathrm{Nrf} 2(+/+)$ and Nrf2 (-/-) mice by streptozotocin injection to determine whether Nrf2 activators sulforaphane or cinnamic aldehyde attenuate renal damage and preserve renal function. ${ }^{73}$ They found that both sulforaphane and cinnamic aldehyde significantly attenuated common metabolic disorder symptoms associated with diabetes in $\mathrm{Nrf} 2(+/+)$ but not in Nrf2 (-/-) mice, suggesting that targeting Nrf2 activation might be used therapeutically to improve metabolic disorders and attenuate renal damage induced by diabetes. ${ }^{73}$

\section{HIVIAIDS}

HIV/AIDS is a chronic immunological condition in which HIV attacks the immune system, which can lead to AIDS. Zhang et al studied the effect of Nrf2 on Tatinduced HIV-1 transcription in multinuclear activation of galactosidase indicator cells. ${ }^{74}$ Their data show that Nrf2 is involved in inhibiting Tat-induced HIV-1 long-terminal repeat transactivation, suggesting that Nrf2 might be an important molecular target for inhibiting HIV-1 transcription. Because evidence suggests that HIV infection causes oxidative stress and damages epithelial barrier function in the lung, Fan et al studied alveolar epithelial cells from HIV-1 transgenic rats cells in vitro and found that Nrf2 activation both improved the expression of tight junction proteins and also restored the ability of the cells to form tight barriers. ${ }^{75}$

\section{Rheumatoid arthritis}

Increasing evidence indicates that oxidative stress may play a key role in the development of rheumatoid arthritis. ${ }^{76,77}$ Wruck et al used antibody-induced arthritis in Nrf2-knockout and Nrf2-wild-type control mice to study the role of Nrf2 against oxidative stress in rheumatoid arthritis; they concluded that oxidative stress is significantly involved in cartilage degradation in experimental arthritis, and the presence of a functional Nrf2 gene is a major requirement for limiting cartilage destruction. ${ }^{78}$ Maicas et al analyzed the relevance of Nrf2 in the effector phase of a rheumatoid arthritis animal model and found that Nrf2 deficiency accelerates the incidence of arthritis and aggravates joint disease. ${ }^{79}$ The results support a protective role for Nrf2 against joint inflammation and degeneration in rheumatoid arthritis. ${ }^{77}$

\section{Neurodegenerative disorders}

In several studies, Nrf2 has been shown to play an important role in mouse models of neurodegenerative diseases such as Parkinson's disease and Huntington's disease. ${ }^{80-83}$ Additionally, Nrf2 has been reported to be relevant to acute neurological disorders such as stroke. ${ }^{84,85}$ Oxidative stress plays an important role in these neurodegenerative disorders, including the degeneration of dopaminergic neurons in Parkinson's disease, ${ }^{86,87}$ and Nrf2 may contribute to the beneficial role of the neuroprotective Parkinson Protein 7 (PARK7, also known as DJ-1). ${ }^{86}$ The protective results from small molecule activators of Nrf2 in neurological disorders such as Parkinson's 
disease provide a rationale for additional disease model studies and the potential for human clinical trials in the future. ${ }^{80}$

\section{Sepsis}

Several studies have outlined a role for Nrf2 in sepsis or Systemic Inflammatory Response Syndrome. ${ }^{88}$ Studies in mouse models have indicated that Nrf2 plays a critical role in improving survival during sepsis. ${ }^{88}$ Recently, Kong et al demonstrated that disruption of Keap1 in leukocytes protected against injury and mortality in a mouse cecal ligation and puncture model of sepsis. Their findings indicate Nrf2 acts as an immunomodulator in leukocytes and protects against sepsis by contributing to control of the host inflammatory response to bacterial infection. ${ }^{89}$

\section{Review of Nrf2 in cancer and chemotherapy}

There have been several interesting publications in recent years pertaining to the role of Nrf 2 in both cancer prevention and in cancer development/progression. ${ }^{90-93}$ This is a very active field of research. ${ }^{94} \mathrm{Nrf} 2$ activation has been shown to have chemopreventive benefits and effects that can support cancer development and progression.

Recent research has indicated a distinctly negative role for persistent Nrf2 activation in some cancer cells. ${ }^{95-98}$ The main idea is that certain types of cancer cells, including some lung, endometrial, skin, breast, and prostate cancers, gain function by constitutively activating the Nrf2 cell survival pathway. ${ }^{90,99-104}$ This can occur by multiple mechanisms including mutations in genes directly involved in the pathway such as Keap 1, ${ }^{102,103,105}$ methylation of genes such as p66Shc (also known as SHCtransforming protein 1) leading to their repression and subsequent overexpression of $\mathrm{Nrf} 2,{ }^{106}$ increased expression of $B c l$ - $x L$ (B-cell lymphoma-extra large), ${ }^{107}$ increased expression of BRCA1 (Breast Cancer 1, Early Onset), ${ }^{108}$ or other mechanisms. For example, the adaptor protein p62 (Sequestosome 1 , SQSTM1) is a target gene for Nrf2 and it is also capable of binding to Keap1, which can lead to a positive feedback loop in its transcriptional regulation and dysregulation of apoptosis and autophagy. ${ }^{93,109,110}$ The net result is that these types of cancer cells remain proliferative in oxidatively-stressed environments, have increased Nrf2-dependent metabolic activities that can support cell proliferation, ${ }^{111}$ and can gain resistance against some types of cancer drugs. ${ }^{101}$

The predominant way that Nrf2 activation has been studied in cancer has been constitutive, continuous utilization of the pathway (for example, through mutations in Keap1 or Nrf2), but there may also be a possible role for increases in Nrf2 signaling in some types of cancer that are not based on Nrf2 or Keap1 mutations. ${ }^{112}$ This differs from the intermittent activation of Nrf2 that occurs naturally through consumption of certain foods (like broccoli) and spices, Nrf2-activating dietary supplements, exercise, and Nrf2activating drugs. The Nrf2 pathway has been described as having hormetic behavior, with beneficial effects observed for intermediate levels of Nrf2 activation and deleterious effects observed when there is too little or too much Nrf2 activation; in addition, it has been proposed that dietary consumption of Nrf2 activators in foods and spices likely falls within the healthy middle part of the activation range. ${ }^{24,113}$ Constitutive Nrf2 activation has been shown to have negative effects, but intermittent activation has not, although it might still have undiscovered negative effects.

Cancer cells that do not constitutively upregulate the Nrf2 pathway might still benefit from its activation by other mechanisms. ${ }^{95}$ It has been shown that Nrf2 activation gives cancer cells a survival benefit ${ }^{95}$ and that Nrf2 activation may also participate in resistance to chemotherapy or radiation therapy. ${ }^{114}$ For example, Nrf2 activation has been shown to contribute to multi-drug resistance to chemotherapeutic agents in cultured H69 lung cancer cells through the Multidrug Resistance Associated Protein 1 gene ( $M R P 1$, also known as $A B C C 1) .{ }^{115}$ This paradigm - that some types of cancer cells may resist chemotherapy by an Nrf2-dependent mechanism - has led to studies that target Nrf2 inactivation in an attempt to make the cancer cells more susceptible to the chemotherapeutic drug. Ren et al used an Nrf2 inhibitor, brusatol, to decrease chemoresistance of cancer cells to treatment with cisplatin and other drugs. ${ }^{116}$

Based on such findings, it may be logical to avoid intentional Nrf2 activation during chemotherapy in case the cancer cells utilize Nrf2 for survival or for drug resistance, or at least attempt targeted strategies that do no benefit the cancer cells. One reason for discontinuing intentional Nrf2 activation during cancer therapy is that it is unclear whether it might alter the chemotherapy or radiotherapy response by the cancer cells and/or normal cells, perhaps allowing cancer cells to gain survival benefit against the therapy. An additional reason is that some chemotherapy agents like tamoxifen are prodrugs that require processing by liver cytochrome P450 enzymes such as CYP2D6, the levels of which might be changed by Nrf2 activation, because this could change the patient's response to the drug. ${ }^{117,118}$ Additionally, other xenobiotic metabolism enzymes such as CYP2A6 can be upregulated by Nrf2 activation and have been implicated in the activation of nitrosamines which could affect levels of carcinogenesis. ${ }^{119,120}$ Notably, Wu et al recently concluded 
that Nrf2 plays a central role in xenobiotic metabolism and detoxification, but that Nrf2 activation had only a modest effect on the regulation of the CYP enzyme genes. ${ }^{121}$

\section{Drugs targeting Nrf2}

Because Nrf2 has been shown to participate in cytoprotection against common pathophysiological pathways involving inflammation and oxidative stress, it has emerged as an attractive drug target. ${ }^{122-127}$ In recent years, research has been highly focused toward the discovery of new Nrf2-related drugs, including high-throughput screening approaches, ${ }^{127-132}$ structure-based modeling, ${ }^{133}$ and the testing and development of molecules that target the Nrf2 pathway. ${ }^{80,134-140}$

\section{Dimethyl fumarate}

Multiple sclerosis (MS) is an inflammatory disease in which the myelin sheaths around nerve cell axons are damaged by the immune system, leading to deterioration of function and to neurological symptoms. About $80 \%$ of MS patients initially present with the relapsing-remitting subtype, which is characterized by disease relapses followed by periods (months to years) of remission, making prevention of relapse/extension of remission period a good target for intervention.

In recent years, an oral formulation of dimethyl fumarate (formerly known as BG-12 and marketed as Tecfidera ${ }^{\circledR}$; Biogen Idec, Inc, Weston, MA, USA), has been developed for treatment of relapsing-remitting MS. ${ }^{141-143}$ Notably, dimethyl fumarate has been shown to activate the Nrf2 pathway in vitro, which is thought to contribute to the drug's dual antiinflammatory and neuroprotective effects. Other mechanisms may also be relevant to the beneficial effects of dimethyl fumarate in MS, including NF- $\kappa$ B inhibition. ${ }^{144}$ In Biogen's DEFINE (Determination of the Efficacy and Safety of Oral Fumarate in Relapsing-Remitting MS) Phase III clinical trial, Tecfidera ${ }^{\circledR}$ significantly reduced the proportion of patients who relapsed within 2 years compared with placebo. ${ }^{145-147}$

After receiving US Food and Drug Administration approval on March 27, 2013, ${ }^{148,149}$ Biogen quickly launched their Nrf2-activating dimethyl fumarate drug (marketed as Tecfidera $^{\circledR}$ ) for treatment of multiple MS into the US market. Interestingly, the drug rapidly became a major sales success in the marketplace by mid-2013. Greatly exceeding expectations, Biogen reported quarterly sales valued at \$192 million for the second quarter (reported on July 25, 2013). ${ }^{150} \mathrm{It}$ remains to be seen whether the volume of sales will continue to increase, but from an Nrf2 science perspective the successful product launch helps validate overall biomedical interest in the Nrf2 signaling pathway. Furthermore, the associated postmarketing surveillance of the new drug will continue to improve knowledge about the efficacy and safety of chronic consumption of Tecfidera ${ }^{\circledR}$ - thought to exert its beneficial effects by acting as a pharmaceutical Nrf2 activator - in a large number of patients.

\section{CDDO-Me}

CDDO-Me (Methyl 2-cyano-3,12-dioxoleana-1,9(11)-dien28-oate, a synthetic oleanane triterpenoid, also known as bardoxolone methyl) has been studied for its Nrf2 activation properties and has been deemed a promising drug candidate for treating many different degenerative illnesses, including diabetic complications. ${ }^{88,151-154}$ Research in animal models of chronic kidney disease (CKD) indicated that functional Nrf2Keap1 signaling is important to limiting the effects of oxidative stress in CKD and its progression. ${ }^{155}$ The agent was also studied in humans, and because CDDO-Me improved the estimated glomerular filtration rate (eGFR) in patients with advanced CKD in a randomized, placebo-controlled Phase II trial, ${ }^{151,152}$ a follow-up Phase III trial enrolling over 2,000 patients was initiated (ClinicalTrials.gov Identifier: NCT01351675). ${ }^{156}$ Unfortunately the CDDO-Me trial was forced by its Independent Data Monitoring Committee to be terminated in November 2012 due to undisclosed safety concerns.

Activation of Nrf2 appears less suitable for reversing advanced pathological conditions than for preventing initial damage or slowing it once it starts. This is evident in the Phase II CDDO-Me clinical results in which patients with early stage CKD showed some benefit in measured eGFR. ${ }^{157}$

One possible reason suggested for the adverse events that halted the CDDO-Me clinical trial was that the measured eGFR benefit was a result of increased intraglomerular pressure leading to not only short-term hyperfiltration but also to longer-term accelerated nephropathy and renal function loss. ${ }^{144,158}$ Another reason is the possibility that CDDO-Me interacts with other targets in addition to the Nrf2 pathway, as has been noted for structurally related compounds. ${ }^{159}$ As noted by Zhang, the original development of CDDO-Me was not specifically targeted at Nrf2 activation, and new efforts at drug discovery might yield comparably effective drugs addressing the Nrf2 pathway, but with fewer off-target effects. ${ }^{157}$

\section{A few examples of potential new agents}

Wang et al recently used a high-throughput screening approach from a synthetic library of 1.2 million small molecule compounds to identify candidate ARE-inducing molecules, and further studied candidate AI-3 (ARE Inducer-3). ${ }^{131}$ The AI-3 molecule was shown to activate Nrf2 by inducing an AREluciferase reporter gene in vitro, by increasing the production 
of ARE-driven NQO1 protein production in cultured cells in vitro, by inducing SKN-1-driven (analog of Nrf2) GST4 in Caenorhabditis elegans in vivo, and by increasing AREregulated NQO1 expression levels in mouse liver and kidney following intraperitoneal injection in vivo. ${ }^{131}$

Recent demonstration of a role for miRNA molecules in the regulation or tuning of Nrf2 activation and signaling ${ }^{30,31}$ suggests a possibility for the development of miRNA-based therapies that address activating or inhibiting the Nrf2 pathway if off-target effect can be avoided.

Traditional Chinese medicine's Si-Wu-Tang (SWT, which translates as Four-Agents-Decoction) $)^{160}$ has been demonstrated by gene array and pathway analysis studies to induce gene expression via the Nrf2 pathway. ${ }^{63} \mathrm{SWT}$ has been used throughout Asia for about 1,000 years for treatment of menstrual symptoms and menopausal difficulties, and continues to play a role in the treatment of estrogen-related illnesses. ${ }^{161-163}$ In recent years SWT has also been shown in mice to have benefit against radiation-induced bone marrow damage. ${ }^{164,165}$

Cureveda LLC is a company (Baltimore, MD, USA) focused on the development of therapeutics targeting the Nrf2 antioxidant pathway. It has reported current activities to develop a small molecule Nrf2 activator called VEDA-1209; preclinical pharmacokinetic and pharmacodynamics testing is underway and studies are planned for testing in animal models of ulcerative colitis.

Evgen Ltd is a company (Liverpool, UK) focused on the development of sulforaphane-based pharmaceuticals. ${ }^{166}$ For new drugs that utilize Nrf2 activation, it has developed a synthetic sulforaphane-cyclodextrin complex, called Sulforadex ${ }^{\circledR}$, with improved shelf stability over sulforaphane alone. It reports completion of a first-in-man clinical study of Sulforadex ${ }^{\circledR}$, and indicates that a prostate cancer trial is planned for 2014.

\section{Potential development of Nrf2 inhibitors}

There are cases where Nrf2 inhibition may be preferable to Nrf2 activation. As noted above, some cancers gain an advantage over therapy by utilizing constitutive Nrf2 activation to enhance survival mechanisms and facilitate increased drug resistance. The idea of inhibiting those mechanisms with another drug while treating with chemotherapy may be worthwhile. Shutting down the Nrf2 signaling pathway might restore chemotherapy sensitivity of some cancer cells, and Nrf2 inhibitors might have benefits against other disease processes as well. ${ }^{116}$ Some candidate inhibitors are summarized in Table 1.
Table I Potential Nrf2 inhibitors

\begin{tabular}{|c|c|}
\hline Retinoic acid & $\begin{array}{l}\text { All-trans retinoic acid was found to inhibit Nrf2- } \\
\text { mediated induction of ARE-driven genes. The } \\
\text { mechanism of retinoid-related Nrf2 repression } \\
\text { involves retinoid X receptor alpha binding to } \\
\text { Nrf2. }{ }^{167,168}\end{array}$ \\
\hline $\begin{array}{l}\text { 6-Hydroxy-I- } \\
\text { methylindole- } \\
\text { 3-acetonitrile } \\
(6-H M A)\end{array}$ & $\begin{array}{l}\text { Protective effects were observed for 6-HMA on } \\
\text { cisplatin-induced oxidative nephrotoxicity via Nrf2 } \\
\text { inactivation. }{ }^{169}\end{array}$ \\
\hline Luteolin & $\begin{array}{l}\text { Luteolin has been shown in separate studies to both } \\
\text { inhibit and activate Nrf2-mediated induction of ARE- } \\
\text { driven genes. }{ }^{170-173}\end{array}$ \\
\hline Bleomycin & $\begin{array}{l}\text { Part of the mechanism of bleomycin-induced } \\
\text { pulmonary fibrosis has been shown to involve } \\
\text { suppression of Nrf2 activation. Although not the } \\
\text { goal of the study, this result suggests the possibility } \\
\text { that bleomycin could be a candidate for Nrf2 } \\
\text { inhibitor drug development. }{ }^{174}\end{array}$ \\
\hline Brusatol & $\begin{array}{l}\text { Brusatol was identified as a selective inhibitor of the } \\
\text { Nrf2 pathway. It acts by increasing ubiquitination } \\
\text { and degradation of Nrf2. In cultured cancer cells } \\
\text { and xenografts, brusatol was shown to decrease } \\
\text { chemoresistance to treatment with cisplatin and } \\
\text { other drugs. }^{116}\end{array}$ \\
\hline
\end{tabular}

Abbreviations: Nrf2, nuclear factor (erythroid-derived 2)-like 2; ARE, antioxidant response element.

\section{Effects of diet, nutritional supplements, and exercise on the Nrf2 pathway Diet}

One interesting aspect of phytochemical activation of the Nrf2 pathway is the possibility that the historical origination of the use of certain Nrf2-activating foods and spices in the human diet could have stemmed from perceived salutary health effects of these agents, ${ }^{175}$ with possible contemporary significance to healthy human diets. ${ }^{176-178}$

Recommendations for influencing Nrf2 activation by dietary means have typically pertained to the demonstrated activity of readily available food products like curcumin from turmeric root and sulforaphane from broccoli and other sources,${ }^{179-181}$ many other relevant whole plant materials and isolated phytochemicals have been identified. ${ }^{24,176}$ In one recent example, seaweed-based extracts (from green alga Ulva lactuca, with focus on monounsaturated fatty acid derivatives, active fraction selected by bioassayguided fractionation) have been shown to activate the Nrf2 pathway, upregulating $\mathrm{Nqol}$ gene transcription in mouse hearts 12 hours after a single gavage treatment in vivo. ${ }^{182} \mathrm{In}$ another recent example, Heber et al found that sulforaphane, 
administered as an extract but given in a dose that could be achieved by dietary broccoli consumption, offered benefits against particulate pollution in human subjects, suggesting that such treatment might be beneficial against asthma or allergies. ${ }^{183}$ Likewise, phytochemical components of garlic, tomatoes, grapes, green tea, coffee, and berries have been shown to have Nrf2 activating properties, ${ }^{184}$ supporting the possibility that dietary means of Nrf2 activation might be a simple but effective strategy for prevention or treatment of illnesses. ${ }^{178,185}$

\section{Dietary supplements}

An extensive amount of research has been done and information gathered about phytochemical activation of $\mathrm{Nrf2}$, with dozens of plant-based activators identified and studied. ${ }^{40,176-178,186-192}$ Since the discovery of Nrf2 and its wellness potential in regulating cell survival genes and protecting tissues against oxidative and other insults, and in light of the phytochemical activation data, several nutritional supplements have been developed to help consumers address health and wellness issues by activating the Nrf2 pathway. ${ }^{40,135}$

Several dietary supplement companies have developed specific mixtures for increasing antioxidant enzyme defenses (some companies working in this space include New Chapter, Inc, LifeVantage, Inc, Xymogen, and Nuley). ${ }^{40,135}$ In each case, a mixture of Nrf2-activating ingredients is blended together. For some of the materials, studies were done to show activity of the mixture, but in other cases reliance was simply made on known properties of the individual ingredients. In at least one case, Protandim (LifeVantage, Inc, Sandy, UT, USA), the complete mixture has been extensively studied, not just the individual ingredients. ${ }^{40,186,191-200}$ Study of the combined ingredients allowed demonstration of synergistic interaction between the ingredients; each of which separately was previously known to be a Nrf2 activator. ${ }^{191}$ Furthermore, as a branded product, Protandim was shown to decrease oxidative stress in laboratory models in vivo, as well as in human subjects. ${ }^{193}$ While some dietary supplement products highlight the role of Nrf2 activation as part of their health and wellness benefit, others (eg, Supercritical Antioxidants; New Chapter, Brattleboro, VT, USA) indicate their antioxidant gene regulation activity without specifying a role for the Nrf2 pathway. Perhaps not surprisingly based on their ingredient profile and reported benefits, some of these products likely also activate the Nrf2 pathway.

To demonstrate Nrf2 activation by two dietary supplements, one marketed as a Nrf2 activator and the other marketed as supportive of antioxidant enzymes, we examined both using a promoter/reporter cell line responsive to Nrf2 activation. Briefly, this widely used assay is based on the AREc32 cell line, developed and generously provided by Dr C R Wolf and colleagues of the University of Dundee. ${ }^{201}$ The AREc32 cell line is based on the MCF7 (Michigan Cancer Foundation-7) human breast cancer cell line, and is stably transfected with a construct containing a promoter with eight copies of the ARE from the rat glutathione-S-transferase-A2 gene, along with the SV40 (Simian virus 40) promoter sequence upstream of a firefly luciferase reporter gene. As shown in Figure 3, both of the tested dietary supplements activated the Nrf2 pathway in the AREc32 cells. This type of experimental approach can be utilized to make comparisons and help define the mechanism for materials purported to increase antioxidant and detoxifying enzymes.

\section{Exercise}

Recently, a relationship between exercise and Nrf2 activation has been demonstrated. ${ }^{200,202-205}$ For example, activation of Nrf2 was induced by acute exercise in a mouse model, and exercise-induced oxidative stress was higher in Nrf2-/- mice

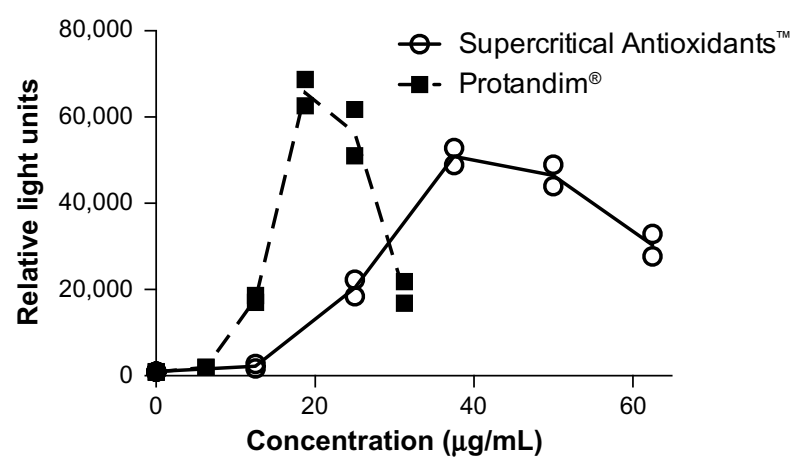

Figure 3 Luciferase activity versus concentration of two nutritional supplements. Notes: Both of the tested nutritional supplements Protandim ${ }^{\circledR}$ (Lifevantage, Inc, Sandy, UT, USA) - reported by the manufacturer to be an Nrf2 activator - and Supercritical Antioxidants ${ }^{\mathrm{TM}}$ (New Chapter, Inc, Brattleboro, VT, USA), not reported by the manufacturer to be an Nrf2 activator - upregulated the Nrf2-driven luciferase reporter gene expression in the AREc32 cell line, depicted as relative light units. Briefly, AREc32 cells were grown by standard methods, then trypsinized, counted and seeded at 20,000 cells/well on 24 -well plates. After 24 hours the cells were reattached and growing, and were treated with varied concentrations of the test material extracts in duplicate. Protandim ${ }^{\circledR}$ was obtained by BG as a gift from Professor Joe McCord; Supercritical Antioxidants ${ }^{\mathrm{TM}}$ was obtained by retail purchase. The agents were extracted overnight with $95 \%$ ethanol in $15 \mathrm{~mL}$ tubes on a rocking table. The extract was obtained by centrifugation and then added to the wells in an appropriate concentration range by dilution into phosphate buffer solution, with final volumes added to culture wells ranging from I to $10 \mu \mathrm{L} /$ well. An ethanol blank at the highest $10 \mu \mathrm{L} /$ well level was used as the zero control. The cells were incubated for 24 hours, then washed and lysed, after which the lysate was assayed for luciferase activity by measuring luciferin-dependent chemiluminescence, reported as relative light units for the contents of each well. Each assay was performed in duplicate. Luciferase activity correlates directly in this case with Nrf2 activation.

Abbreviations: Nrf2, nuclear factor (erythroid-derived 2)-like 2; ARE, antioxidant response element. 
due to lower expression of Nrf2-dependent antioxidant genes. ${ }^{204}$ Notably, results from Gounder et al indicate that age-related impairment of Nrf2 signaling and antioxidant enzyme pathways may contribute to increased cardiovascular disease risk in the elderly, but that this deficit was reversible in old mice subjected to moderate physical exercise, restoring their heart Nrf2-dependent antioxidants to near-normal, young mouse levels. ${ }^{202}$

\section{Genes downregulated by $\mathrm{Nr} 2$ activation}

One interesting concept that has not had very much coverage in the literature is downregulation of gene expression by $\mathrm{Nrf} 2$ activation. Previous work by ourselves and others has shown that Nrf2 activation upregulates the expression of hundreds of genes, ${ }^{26,40,206,207}$ but another direct or indirect consequence of Nrf2 activation is the downregulation of a large number of genes. ${ }^{3,40}$ In most cases, this downregulation is likely a consequence of downstream effects of Nrf2 activation and its regulation of genes that subsequently lead to downregulation of other genes, but the possibility also exists that Nrf2 binding to some ARE sequences of genes directly suppresses their transcription. For example, in work by Jiang et al, a possible negative regulation of TGF $\beta 1$ (transforming growth factor beta 1) by Nrf2 activation was observed, raising the question of whether Nrf2 negatively regulates TGF $\beta 1$ expression by direct binding to the promoter region of its gene or by other, downstream effects. ${ }^{208}$ Furthermore, treatment of cultured mouse hepatoma cells with the Nrf2 activator diethyl maleate induced genes related to antioxidant, detoxification, and other functions, but also repressed some genes, including ones that contain Nrf2-MafG or Nrf2 binding sites $;^{3}$ however, the mechanism of repression is not yet clear.

Identification of genes directly regulated by Nrf2 requires both sequence verification of a suitably located ARE motif and evidence of $\mathrm{Nrf} 2$ binding and transcriptional activation. Accordingly, Chorley et al conducted ChIP-Seq experiments in lymphoid cells treated with the known Nrf2-activator sulforaphane, and also carried out follow-up Illumina human Ref-8 microarrays to assess Nrf2-mediated gene expression in the six sequenced lines. ${ }^{26}$ They found 242 high confidence, Nrf2-bound genomic regions and the expressions of 508 genes changed by 1.3 -fold or greater. Among genes with both ChIPSeq peaks and gene expression changes, there were significantly more ChIP-Seq peak regions near upregulated genes $(20.6 \%$; $60 / 291)$ than downregulated genes $(4.6 \% ; 10 / 217 ; P<0.0001$, Fisher's exact test). ${ }^{26}$ Notably, none of the downregulated genes displayed high-confidence ChIP-Seq peaks, suggesting that the downregulation of these genes may be due to secondary, downstream effects rather than direct effects of Nrf2 binding.
Fourtounis et al reported downregulation of Eotaxin-1/ CCL11 in human lung fibroblasts by small interfering RNA (siRNA) to inhibit Keap1 and also by treatment with known Nrf2 activators sulforaphane and CDDO. ${ }^{35}$ Briefly, they used a custom Affymetrix Gene array to study gene expression in normal human lung fibroblasts transfected with siRNA specific for Nrf2 or Keap1, or treated with the small molecule Nrf2 activators sulforaphane or CDDO. The key eosinophil chemokine Eotaxin-1/CCL11 was found to be upregulated when Nrf2 was inhibited and downregulated when Keap1 was inhibited, whereas no effect had been found on the secretion of a set of other chemokines and cytokines. Furthermore, the known Nrf2 small molecule activators CDDO and sulphoraphane dose-dependently inhibited Eotaxin-1 release from human lung fibroblasts. The mechanism for Eotaxin regulation by $\mathrm{Nrf} 2$ is not known. For example, an ARE motif was not found in the $5^{\prime}$ region upstream of the human Eotaxin-1 gene, suggesting that its downregulation by Nrf2 may be an indirect effect, possibly as a downstream effect of $\mathrm{NF}-\kappa \mathrm{B}$ inhibition or other antiinflammatory signaling. ${ }^{35}$

\section{Conclusion}

The Nrf2 cell signaling pathway has been demonstrated to contribute to the regulation of a wide variety of antioxidant, detoxification, and cell survival genes. Under normal conditions, Nrf2 activation plays a largely protective, beneficial role, which has led researchers to examine ways in which individuals might harness Nrf2 activation for health benefits, including exercise, diet, dietary supplements, and pharmaceuticals. However, in other instances Nrf2 inhibition may be therapeutic. Efforts at laboratories around the world are underway to develop new agents for either activation or inhibition of the Nrf2 pathway and to demonstrate their efficacy for the treatment of degenerative and immunological disorders.

\section{Acknowledgments}

The authors thank Dr Joe McCord (University of Colorado) for helpful discussions.

\section{Disclosure}

$\mathrm{BMH}$ has received payment for serving on the Scientific Advisory Board for LifeVantage, Inc. The authors report no other conflicts of interest in this work.

\section{References}

1. Venugopal R, Jaiswal AK. Nrf1 and Nrf2 positively and c-Fos and Fra1 negatively regulate the human antioxidant response element-mediated expression of $\mathrm{NAD}(\mathrm{P}) \mathrm{H}$ : quinone oxidoreductase 1 gene. Proc Natl Acad Sci U SA. 1996;93(25):14960-14965. 
2. Itoh K, Chiba T, Takahashi S, et al. An Nrf2/small Maf heterodimer mediates the induction of phase II detoxifying enzyme genes through antioxidant response elements. Biochem Biophys Res Commun. 1997;236(2):313-322.

3. Hirotsu Y, Katsuoka F, Funayama R, et al. Nrf2-MafG heterodimers contribute globally to antioxidant and metabolic networks. Nucleic Acids Res. 2012;40(20):10228-10239.

4. Rushmore TH, Morton MR, Pickett CB. The antioxidant responsive element. Activation by oxidative stress and identification of the DNA consensus sequence required for functional activity. J Biol Chem. 1991;266(18):11632-11639.

5. Friling RS, Bensimon A, Tichauer Y, Daniel V. Xenobiotic-inducible expression of murine glutathione S-transferase Ya subunit gene is controlled by an electrophile-responsive element. Proc Natl Acad Sci US A. 1990;87(16):6258-6262.

6. Prestera T, Talalay P, Alam J, Ahn YI, Lee PJ, Choi AM. Parallel induction of heme oxygenase- 1 and chemoprotective phase 2 enzymes by electrophiles and antioxidants: regulation by upstream antioxidantresponsive elements (ARE). Mol Med. 1995;1(7):827-837.

7. Nerland DE. The antioxidant/electrophile response element motif. Drug Metab Rev. 2007;39(1):235-248.

8. Wasserman WW, Fahl WE. Functional antioxidant responsive elements. Proc Natl Acad Sci U S A. 1997;94(10):5361-5366.

9. Moi P, Chan K, Asunis I, Cao A, Kan YW. Isolation of NF-E2-related factor 2 (Nrf2), a NF-E2-like basic leucine zipper transcriptional activator that binds to the tandem NF-E2/AP1 repeat of the beta-globin locus control region. Proc Natl Acad Sci U S A. 1994;91(21):9926-9930.

10. Rushmore TH, King RG, Paulson KE, Pickett CB. Regulation of glutathione S-transferase Ya subunit gene expression: identification of a unique xenobiotic-responsive element controlling inducible expression by planar aromatic compounds. Proc Natl Acad Sci US A. 1990;87(10):3826-3830.

11. Rushmore TH, Pickett CB. Transcriptional regulation of the rat glutathione S-transferase Ya subunit gene. Characterization of a xenobiotic-responsive element controlling inducible expression by phenolic antioxidants. J Biol Chem. 1990;265(24):14648-14653.

12. Prestera T, Holtzclaw WD, Zhang Y, Talalay P. Chemical and molecular regulation of enzymes that detoxify carcinogens. Proc Natl Acad Sci US A. 1993;90(7):2965-2969.

13. Prestera T, Talalay P. Electrophile and antioxidant regulation of enzymes that detoxify carcinogens. Proc Natl Acad Sci U S A. 1995;92(19):8965-8969.

14. Itoh K, Wakabayashi N, Katoh Y, et al. Keap1 represses nuclear activation of antioxidant responsive elements by Nrf2 through binding to the amino-terminal Neh2 domain. Genes Dev. 1999;13(1):76-86.

15. Itoh K, Mimura J, Yamamoto M. Discovery of the negative regulator of Nrf2, Keap1: a historical overview. Antioxid Redox Signal. 2010;13(11):1665-1678.

16. Kobayashi M, Li L, Iwamoto N, et al. The antioxidant defense system Keap1-Nrf2 comprises a multiple sensing mechanism for responding to a wide range of chemical compounds. Mol Cell Biol. 2009;29(2):493-502.

17. Kobayashi A, Kang MI, Watai Y, et al. Oxidative and electrophilic stresses activate Nrf2 through inhibition of ubiquitination activity of Keap1. Mol Cell Biol. 2006;26(1):221-229.

18. Kobayashi M, Yamamoto M. Nrf2-Keap1 regulation of cellular defense mechanisms against electrophiles and reactive oxygen species. $A d v$ Enzyme Regul. 2006;46:113-140.

19. Takaya K, Suzuki T, Motohashi H, et al. Validation of the multiple sensor mechanism of the Keap1-Nrf2 system. Free Radic Biol Med. 2012;53(4):817-827.

20. Huang HC, Nguyen T, Pickett CB. Regulation of the antioxidant response element by protein kinase C-mediated phosphorylation of NF-E2-related factor 2. Proc Natl Acad Sci U S A. 2000;97(23):12475-12480.

21. Huang HC, Nguyen T, Pickett CB. Phosphorylation of Nrf2 at Ser-40 by protein kinase $\mathrm{C}$ regulates antioxidant response element-mediated transcription. J Biol Chem. 2002;277(45):42769-42774.
22. Sun Z, Huang Z, Zhang DD. Phosphorylation of Nrf2 at multiple sites by MAP kinases has a limited contribution in modulating the Nrf2dependent antioxidant response. PLoS One. 2009;4(8):e6588.

23. Chen HH, Chen YT, Huang YW, Tsai HJ, Kuo CC. 4-Ketopinoresinol, a novel naturally occurring ARE activator, induces the $\mathrm{Nrf} 2 / \mathrm{HO}-1$ axis and protects against oxidative stress-induced cell injury via activation of PI3K/AKT signaling. Free Radic Biol Med. 2012;52(6): 1054-1066.

24. Kumar H, Kim IS, More SV, Kim BW, Choi DK. Natural productderived pharmacological modulators of Nrf2/ARE pathway for chronic diseases. Nat Prod Rep. 2014;31(1):109-139.

25. Doyle K, Fitzpatrick FA. Redox signaling, alkylation (carbonylation) of conserved cysteines inactivates class I histone deacetylases 1, 2, and 3 and antagonizes their transcriptional repressor function. J Biol Chem. 2010;285(23):17417-17424.

26. Chorley BN, Campbell MR, Wang X, et al. Identification of novel NRF2-regulated genes by ChIP-Seq: influence on retinoid $\mathrm{X}$ receptor alpha. Nucleic Acids Res. 2012;40(15):7416-7429.

27. Kimura M, Yamamoto T, Zhang J, et al. Molecular basis distinguishing the DNA binding profile of Nrf2-Maf heterodimer from that of Maf homodimer. J Biol Chem. 2007;282(46):33681-33690.

28. Kaspar JW, Niture SK, Jaiswal AK. Antioxidant-induced INrf2 (Keap1) tyrosine 85 phosphorylation controls the nuclear export and degradation of the INrf2-Cul3-Rbx1 complex to allow normal Nrf2 activation and repression. J Cell Sci. 2012;125(Pt 4):1027-1038.

29. Sun Z, Zhang S, Chan JY, Zhang DD. Keap1 controls postinduction repression of the Nrf2-mediated antioxidant response by escorting nuclear export of Nrf2. Mol Cell Biol. 2007;27(18):6334-6349.

30. Narasimhan M, Patel D, Vedpathak D, Rathinam M, Henderson G, Mahimainathan L. Identification of novel microRNAs in posttranscriptional control of Nrf2 expression and redox homeostasis in neuronal, SH-SY5Y cells. PLoS One. 2012;7(12):e51111.

31. Cheng X, Ku CH, Siow RC. Regulation of the Nrf2 antioxidant pathway by microRNAs: New players in micromanaging redox homeostasis. Free Radic Biol Med. 2013;64:4-11.

32. Chepelev NL, Zhang H, Liu H, et al. Competition of nuclear factorerythroid 2 factors related transcription factor isoforms, Nrf1 and Nrf2, in antioxidant enzyme induction. Redox Biol. 2013;1(1):183-189.

33. Ohtsuji M, Katsuoka F, Kobayashi A, Aburatani H, Hayes JD, Yamamoto M. Nrfl and Nrf2 play distinct roles in activation of antioxidant response element-dependent genes. J Biol Chem. 2008;283(48):33554-33562.

34. Thimmulappa RK, Mai KH, Srisuma S, Kensler TW, Yamamoto M, Biswal S. Identification of Nrf2-regulated genes induced by the chemopreventive agent sulforaphane by oligonucleotide microarray. Cancer Res. 2002;62(18):5196-5203.

35. Fourtounis J, Wang IM, Mathieu MC, et al. Gene expression profiling following NRF2 and KEAP1 siRNA knockdown in human lung fibroblasts identifies CCL11/Eotaxin-1 as a novel NRF2 regulated gene. Respir Res. 2012;13:92.

36. Cho HY, Reddy SP, Debiase A, Yamamoto M, Kleeberger SR. Gene expression profiling of NRF2-mediated protection against oxidative injury. Free Radic Biol Med. 2005;38(3):325-343.

37. Baird L, Dinkova-Kostova AT. The cytoprotective role of the Keap1-Nrf2 pathway. Arch Toxicol. 2011;85(4):241-272.

38. Wakabayashi N, Slocum SL, Skoko JJ, Shin S, Kensler TW. When NRF2 talks, who's listening? Antioxid Redox Signal. 2010;13(11): 1649-1663.

39. Bryan HK, Olayanju A, Goldring CE, Park BK. The Nrf2 cell defence pathway: Keap1-dependent and -independent mechanisms of regulation. Biochem Pharmacol. 2013;85(6):705-717.

40. Hybertson BM, Gao B, Bose SK, McCord JM. Oxidative stress in health and disease: The therapeutic potential of Nrf2 activation. Mol Aspects Med. 2011;32(4-6):234-246.

41. Schneider TD, Stephens RM. Sequence logos: a new way to display consensus sequences. Nucleic Acids Res. 1990;18(20):6097-6100.

42. Crooks GE, Hon G, Chandonia JM, Brenner SE. WebLogo: a sequence logo generator. Genome Res. 2004;14(6):1188-1190. 
43. Ho Sui SJ, Fulton DL, Arenillas DJ, Kwon AT, Wasserman WW. oPOSSUM: integrated tools for analysis of regulatory motif overrepresentation. Nucleic Acids Res. 2007;35(Web Server issue): W245-W252.

44. Kwon AT, Arenillas DJ, Worsley Hunt R, Wasserman WW. oPOSSUM-3: advanced analysis of regulatory motif over-representation across genes or ChIP-Seq datasets. G3 (Bethesda). 2012;2(9):987-1002.

45. Malhotra D, Portales-Casamar E, Singh A, et al. Global mapping of binding sites for Nrf2 identifies novel targets in cell survival response through ChIP-Seq profiling and network analysis. Nucleic Acids Res. 2010;38(17):5718-5734.

46. Benson AM, Hunkeler MJ, Talalay P. Increase of NAD(P)H: quinone reductase by dietary antioxidants: possible role in protection against carcinogenesis and toxicity. Proc Natl Acad Sci U S A. 1980;77(9): 5216-5220.

47. Yates MS, Tran QT, Dolan PM, et al. Genetic versus chemoprotective activation of Nrf2 signaling: overlapping yet distinct gene expression profiles between Keap1 knockout and triterpenoid-treated mice. Carcinogenesis. 2009;30(6):1024-1031.

48. Pae CU, Yu HS, Kim JJ, et al. Quinone oxidoreductase (NQO1) gene polymorphism $(609 \mathrm{C} / \mathrm{T})$ may be associated with tardive dyskinesia, but not with the development of schizophrenia. Int JNeuropsychopharmacol. 2004;7(4):495-500.

49. Kummarapurugu AB, Fischer BM, Zheng S, et al. NADPH:quinone oxidoreductase 1 regulates host susceptibility to ozone via isoprostane generation. J Biol Chem. 2013;288(7):4681-4691.

50. Ouerhani S, Cherif N, Bahri I, Safra I, Menif S, Abbes S. Genetic polymorphisms of NQO1, CYP1A1 and TPMT and susceptibility to acute lymphoblastic leukemia in a Tunisian population. Mol Biol Rep. 2013;40(2):1307-1314.

51. Yanling H, Yuhong Z, Wenwu H, Lei X, Mingwu C. NQO1 C609T polymorphism and esophageal cancer risk: a HuGE review and metaanalysis. BMC Med Genet. 2013;14:31.

52. Asher G, Tsvetkov P, Kahana C, Shaul Y. A mechanism of ubiquitinindependent proteasomal degradation of the tumor suppressors $\mathrm{p} 53$ and p73. Genes Dev. 2005;19(3):316-321.

53. Jung KA, Choi BH, Nam CW, et al. Identification of aldo-keto reductases as NRF2-target marker genes in human cells. Toxicol Lett. 2013;218(1):39-49.

54. Barski OA, Tipparaju SM, Bhatnagar A. The aldo-keto reductase superfamily and its role in drug metabolism and detoxification. Drug Metab Rev. 2008;40(4):553-624.

55. Ryter SW, Choi AM. Heme oxygenase-1/carbon monoxide: novel therapeutic strategies in critical care medicine. Curr Drug Targets. 2010;11(12):1485-1494.

56. Maines MD. The heme oxygenase system: a regulator of second messenger gases. Annu Rev Pharmacol Toxicol. 1997;37:517-554.

57. Barbagallo I, Galvano F, Frigiola A, et al. Potential therapeutic effects of natural heme oxygenase-1 inducers in cardiovascular diseases. Antioxid Redox Signal. 2013;18(5):507-521.

58. Foresti R, Bains SK, Pitchumony TS, et al. Small molecule activators of the Nrf2-HO-1 antioxidant axis modulate heme metabolism and inflammation in BV2 microglia cells. Pharmacol Res. 2013;76:132-148.

59. Kwak MK, Wakabayashi N, Itoh K, Motohashi H, Yamamoto M, Kensler TW. Modulation of gene expression by cancer chemopreventive dithiolethiones through the Keap1-Nrf2 pathway. Identification of novel gene clusters for cell survival. J Biol Chem. 2003;278(10): $8135-8145$

60. Harvey CJ, Thimmulappa RK, Singh A, et al. Nrf2-regulated glutathione recycling independent of biosynthesis is critical for cell survival during oxidative stress. Free Radic Biol Med. 2009;46(4):443-453.

61. Sasaki H, Sato H, Kuriyama-Matsumura K, et al. Electrophile response element-mediated induction of the cystine/glutamate exchange transporter gene expression. J Biol Chem. 2002;277(47):44765-44771.

62. Lewerenz J, Albrecht $\mathrm{P}$, Tien ML, et al. Induction of Nrf2 and $\mathrm{xCT}$ are involved in the action of the neuroprotective antibiotic ceftriaxone in vitro. J Neurochem. 2009;111(2):332-343.
63. Wen Z, Wang Z, Wang S, et al. Discovery of molecular mechanisms of traditional Chinese medicinal formula $\mathrm{Si}$-Wu-Tang using gene expression microarray and connectivity map. PLoS One. 2011;6(3): e18278.

64. Collins AR, Gupte AA, Ji R, et al. Myeloid deletion of nuclear factor erythroid 2-related factor 2 increases atherosclerosis and liver injury. Arterioscler Thromb Vasc Biol. 2012;32(12):2839-2846.

65. Ruotsalainen AK, Inkala M, Partanen ME, et al. The absence of macrophage Nrf2 promotes early atherogenesis. Cardiovasc Res. 2013;98(1):107-115.

66. Barajas B, Che N, Yin F, et al. NF-E2-related factor 2 promotes atherosclerosis by effects on plasma lipoproteins and cholesterol transport that overshadow antioxidant protection. Arterioscler Thromb Vasc Biol. 2011;31(1):58-66.

67. Araujo JA, Zhang M, Yin F. Heme oxygenase-1, oxidation, inflammation, and atherosclerosis. Front Pharmacol. 2012;3:119.

68. Khor TO, Huang MT, Kwon KH, Chan JY, Reddy BS, Kong AN. Nrf2-deficient mice have an increased susceptibility to dextran sulfate sodium-induced colitis. Cancer Res. 2006;66(24):11580-11584.

69. Arisawa T, Tahara T, Shibata T, et al. Nrf2 gene promoter polymorphism is associated with ulcerative colitis in a Japanese population. Hepatogastroenterology. 2008;55(82-83):394-397.

70. Zhu H, Li YR. Oxidative stress and redox signaling mechanisms of inflammatory bowel disease: updated experimental and clinical evidence. Exp Biol Med (Maywood). 2012;237(5):474-480.

71. Ogasawara A, Simizu S, Ito A, et al. Inhibition of NO-induced $\beta$-cell death by novel NF- $\kappa B$ inhibitor (-)-DHMEQ via activation of Nrf2-ARE pathway. Biochem Biophys Res Commun. 2013;433(2): 181-187.

72. Tan Y, Ichikawa T, Li J, et al. Diabetic downregulation of Nrf2 activity via ERK contributes to oxidative stress-induced insulin resistance in cardiac cells in vitro and in vivo. Diabetes. 2011;60(2):625-633.

73. Zheng H, Whitman SA, Wu W, et al. Therapeutic potential of Nrf2 activators in streptozotocin-induced diabetic nephropathy. Diabetes. 2011;60(11):3055-3066.

74. Zhang HS, Li HY, Zhou Y, Wu MR, Zhou HS. Nrf2 is involved in inhibiting Tat-induced HIV-1 long terminal repeat transactivation. Free Radic Biol Med. 2009;47(3):261-268.

75. Fan X, Staitieh BS, Jensen JS, et al. Activating the Nrf2-mediated antioxidant response element restores barrier function in the alveolar epithelium of HIV-1 transgenic rats. Am J Physiol Lung Cell Mol Physiol. 2013;305(3):L267-L277.

76. Healy ZR, Lee NH, Gao X, et al. Divergent responses of chondrocytes and endothelial cells to shear stress: cross-talk among COX-2, the phase 2 response, and apoptosis. Proc Natl Acad Sci U S A. 2005;102(39):14010-14015.

77. Kim J, Cha YN, Surh YJ. A protective role of nuclear factor-erythroid 2-related factor-2 (Nrf2) in inflammatory disorders. Mutat Res. 2010;690(1-2):12-23.

78. Wruck CJ, Fragoulis A, Gurzynski A, et al. Role of oxidative stress in rheumatoid arthritis: insights from the Nrf2-knockout mice. Ann Rheum Dis. 2011;70(5):844-850.

79. Maicas N, Ferrandiz ML, Brines R, et al. Deficiency of Nrf2 accelerates the effector phase of arthritis and aggravates joint disease. Antioxid Redox Signal. 2011;15(4):889-901.

80. Kaidery NA, Banerjee R, Yang L, et al. Targeting Nrf2-mediated gene transcription by extremely potent synthetic triterpenoids attenuate dopaminergic neurotoxicity in the MPTP mouse model of Parkinson's disease. Antioxid Redox Signal. 2013;18(2):139-157.

81. Rojo AI, Innamorato NG, Martín-Moreno AM, De Ceballos ML, Yamamoto M, Cuadrado A. Nrf2 regulates microglial dynamics and neuroinflammation in experimental Parkinson's disease. Glia. 2012;58(5):588-598.

82. Lin MT, Beal MF. Mitochondrial dysfunction and oxidative stress in neurodegenerative diseases. Nature. 2006;443(7113):787-795.

83. Browne SE, Beal MF. Oxidative damage in Huntington's disease pathogenesis. Antioxid Redox Signal. 2006;8(11-12):2061-2073. 
84. Harada N, Ito K, Hosoya T, et al. Nrf2 in bone marrow-derived cells positively contributes to the advanced stage of atherosclerotic plaque formation. Free Radic Biol Med. 2012;53(12):2256-2262.

85. Chapple SJ, Siow RC, Mann GE. Crosstalk between Nrf2 and the proteasome: Therapeutic potential of Nrf2 inducers in vascular disease and aging. Int J Biochem Cell Biol. 2012;44(8):1315-1320.

86. Dias V, Junn E, Mouradian MM. The role of oxidative stress in Parkinson's disease. J Parkinsons Dis. 2013;3(4):461-491.

87. Jin H, Kanthasamy A, Ghosh A, Anantharam V, Kalyanaraman B, Kanthasamy AG. Mitochondria-targeted antioxidants for treatment of Parkinson's disease: Preclinical and clinical outcomes. Biochim Biophys Acta. Epub September 20, 2013.

88. Thimmulappa RK, Fuchs RJ, Malhotra D, et al. Preclinical evaluation of targeting the Nrf2 pathway by triterpenoids (CDDO-Im and CDDO-Me) for protection from LPS-induced inflammatory response and reactive oxygen species in human peripheral blood mononuclear cells and neutrophils. Antioxid Redox Signal. 2007;9(11):1963-1970.

89. Kong X, Thimmulappa R, Craciun F, et al. Enhancing Nrf2 pathway by disruption of Keap1 in myeloid leukocytes protects against sepsis. Am J Respir Crit Care Med. 2011;184(8):928-938.

90. Lau A, Villeneuve NF, Sun Z, Wong PK, Zhang DD. Dual roles of Nrf2 in cancer. Pharmacol Res. 2008;58(5-6):262-270.

91. Eggler AL, Gay KA, Mesecar AD. Molecular mechanisms of natural products in chemoprevention: induction of cytoprotective enzymes by Nrf2. Mol Nutr Food Res. 2008;52 Suppl 1:S84-S94.

92. Suzuki T, Motohashi H, Yamamoto M. Toward clinical application of the Keap1-Nrf2 pathway. Trends Pharmacol Sci. 2013;34(6):340-346.

93. Ganan-Gomez I, Wei Y, Yang H, Boyano-Adanez MC, Garcia-Manero G. Oncogenic functions of the transcription factor Nrf2. Free Radic Biol Med. 2013;65:750-764.

94. Ma Q, He X. Molecular basis of electrophilic and oxidative defense: promises and perils of Nrf2. Pharmacol Rev. 2012;64(4): 1055-1081.

95. Shelton $P$, Jaiswal AK. The transcription factor NF-E2-related factor 2 (Nrf2): a protooncogene? FASEB J. 2013;27(2):414-423.

96. Shen H, Zhou S, Wang J. The paradoxical role of Nrf2 in tumor biology. Crit Rev Eukaryot Gene Expr. 2013;23(1):37-47.

97. Bauer AK, Hill T, Alexander CM. The involvement of NRF2 in lung cancer. Oxid Med Cell Longev. 2013;2013:746432.

98. Mitsuishi Y, Motohashi H, Yamamoto M. The Keap1-Nrf2 system in cancers: stress response and anabolic metabolism. Front Oncol. 2012;2:200

99. Zhang DD. The Nrf2-Keap1-ARE signaling pathway: the regulation and dual function of Nrf2 in cancer. Antioxid Redox Signal. 2010;13(11):1623-1626.

100. Jiang T, Chen N, Zhao F, et al. High levels of Nrf2 determine chemoresistance in type II endometrial cancer. Cancer Res. 2010;70(13):5486-5496.

101. Wang XJ, Sun Z, Villeneuve NF, et al. Nrf2 enhances resistance of cancer cells to chemotherapeutic drugs, the dark side of Nrf2. Carcinogenesis. 2008;29(6):1235-1243.

102. Miura S, Shibazaki M, Kasai S, et al. A somatic mutation of the Keap1 gene in malignant melanoma is involved in aberrant NRF2 activation and an increase of intrinsic drug resistance. J Invest Dermatol. Epub August 12, 2013

103. Yamadori T, Ishii Y, Homma S, et al. Molecular mechanisms for the regulation of Nrf2-mediated cell proliferation in non-small-cell lung cancers. Oncogene. 2012;31(45):4768-4777.

104. Homma S, Ishii Y, Morishima Y, et al. Nrf2 enhances cell proliferation and resistance to anticancer drugs in human lung cancer. Clin Cancer Res. 2009;15(10):3423-3432.

105. Singh A, Misra V, Thimmulappa RK, et al. Dysfunctional KEAP1-NRF2 interaction in non-small-cell lung cancer. PLoS Med. 2006;3(10):e420.

106. Du W, Jiang Y, Zheng Z, et al. Feedback loop between p66 and Nrf2 promotes lung cancer progression. Cancer Lett. 2013;337(1): $58-65$.
107. Niture SK, Jaiswal AK. Nrf2-induced antiapoptotic Bcl-xL protein enhances cell survival and drug resistance. Free Radic Biol Med. 2013;57:119-131.

108. Wang Q, Li J, Yang X, et al. Nrf2 is associated with the regulation of basal transcription activity of the BRCA1 gene. Acta Biochim Biophys Sin (Shanghai). 2013;45(3):179-187.

109. Stępkowski TM, Kruszewski MK. Molecular cross-talk between the NRF2/KEAP1 signaling pathway, autophagy, and apoptosis. Free Radic Biol Med. 2011;50(9):1186-1195

110. Komatsu M, Kurokawa H, Waguri S, et al. The selective autophagy substrate p62 activates the stress responsive transcription factor Nrf2 through inactivation of Keap1. Nat Cell Biol. 2010;12(3): 213-223.

111. Mitsuishi Y, Taguchi K, Kawatani Y, et al. Nrf2 redirects glucose and glutamine into anabolic pathways in metabolic reprogramming. Cancer Cell. 2012;22(1):66-79.

112. Satoh H, Moriguchi T, Takai J, Ebina M, Yamamoto M. Nrf2 Prevents Initiation but Accelerates Progression through the Kras Signaling Pathway during Lung Carcinogenesis. Cancer Res. 2013;73(13): 4158-4168.

113. Maher J, Yamamoto M. The rise of antioxidant signaling - the evolution and hormetic actions of Nrf2. Toxicol Appl Pharmacol. 2010;244(1):4-15.

114. Singh A, Bodas M, Wakabayashi N, Bunz F, Biswal S. Gain of Nrf2 function in Non-Small-Cell Lung Cancer Cells Confers Radioresistance. Antioxid Redox Signal. 2010;13(11):1627-1637.

115. Ji L, Li H, Gao P, et al. Nrf2 pathway regulates multidrug-resistanceassociated protein 1 in small cell lung cancer. PLoS One. 2013;8(5): e63404.

116. Ren D, Villeneuve NF, Jiang T, et al. Brusatol enhances the efficacy of chemotherapy by inhibiting the Nrf2-mediated defense mechanism. Proc Natl Acad Sci U S A. 2011;108(4):1433-1438.

117. Misaka S, Kawabe K, Onoue S, et al. Effects of green tea catechins on cytochrome P450 2B6, 2C8, 2C19, 2D6 and 3A activities in human liver and intestinal microsomes. Drug Metab Pharmacokinet. 2013;28(3):244-249.

118. Saladores PH, Precht JC, Schroth W, Brauch H, Schwab M. Impact of metabolizing enzymes on drug response of endocrine therapy in breast cancer. Expert Rev Mol Diagn. 2013;13(4):349-365.

119. Yamazaki H, Inui Y, Yun CH, Guengerich FP, Shimada T. Cytochrome P450 2E1 and 2A6 enzymes as major catalysts for metabolic activation of N-nitrosodialkylamines and tobacco-related nitrosamines in human liver microsomes. Carcinogenesis. 1992;13(10):1789-1794.

120. Yokota S, Higashi E, Fukami T, Yokoi T, Nakajima M. Human CYP2A6 is regulated by nuclear factor-erythroid 2 related factor 2. Biochem Pharmacol. 2011;81(2):289-294.

121. Wu KC, Cui JY, Klaassen CD. Effect of graded Nrf2 activation on phase-I and -II drug metabolizing enzymes and transporters in mouse liver. PLoS One. 2012;7(7):e39006.

122. Magesh S, Chen Y, Hu L. Small molecule modulators of Keap1-Nrf2ARE pathway as potential preventive and therapeutic agents. Med Res Rev. 2012;32(4):687-726.

123. Li J, Ichikawa T, Janicki JS, Cui T. Targeting the Nrf2 pathway against cardiovascular disease. Expert Opin Ther Targets. 2009;13(7): 785-794.

124. Hur J, Pak SC, Koo BS, Jeon S. Borneol alleviates oxidative stress via upregulation of Nrf2 and Bcl-2 in SH-SY5Y cells. Pharm Biol. 2013;51(1):30-35.

125. Calkins MJ, Johnson DA, Townsend JA, et al. The Nrf2/ARE pathway as a potential therapeutic target in neurodegenerative disease. Antioxid Redox Signal. 2009;11(3):497-508.

126. Ashrafian H, Czibik G, Bellahcene M, et al. Fumarate is cardioprotective via activation of the Nrf2 antioxidant pathway. Cell Metab. 2012;15(3):361-371.

127. Hur W, Sun Z, Jiang T, et al. A small-molecule inducer of the antioxidant response element. Chem Biol. 2010;17(5):537-547.

128. Smirnova NA, Haskew-Layton RE, Basso M, et al. Development of Neh2-luciferase reporter and its application for high throughput screening and real-time monitoring of Nrf2 activators. Chem Biol. 2011;18(6):752-765. 
129. Leung CK, Deonarine A, Strange K, Choe KP. High-throughput screening and biosensing with fluorescent C. elegans strains. J Vis Exp. 2011;(51).

130. Hu L, Magesh S, Chen L, et al. Discovery of a small-molecule inhibitor and cellular probe of Keap1-Nrf2 protein-protein interaction. Bioorg Med Chem Lett. 2013;23(10):3039-3043.

131. Wang R, Mason DE, Choe KP, Lewin AS, Peters EC, Luesch H. In vitro and in vivo characterization of a tunable dual-reactivity probe of the Nrf2-ARE pathway. ACS Chem Biol. 2013;8(8): 1764-1774.

132. Hur W, Gray NS. Small molecule modulators of antioxidant response pathway. Curr Opin Chem Biol. 2011;15(1):162-173.

133. Williamson TP, Amirahmadi S, Joshi G, et al. Discovery of potent, novel Nrf2 inducers via quantum modeling, virtual screening, and in vitro experimental validation. Chem Biol Drug Des. 2012;80(6): 810-820.

134. Wu KC, McDonald PR, Liu JJ, Chaguturu R, Klaassen CD. Implementation of a high-throughput screen for identifying small molecules to activate the Keap1-Nrf2-ARE pathway. PLoS One. 2012;7(10):e44686.

135. Zenkov NK, Menshchikova EB, Tkachev VO. Keap1/Nrf2/ARE redoxsensitive signaling system as a pharmacological target. Biochemistry (Mosc). 2013;78(1):19-36.

136. Kobayashi M. Harnessing the antioxidant power with ARE-inducing compounds. Chem Biol. 2010;17(5):419-420.

137. Tanaka A, Hamada N, Fujita Y, et al. A novel kavalactone derivative protects against $\mathrm{H} 2 \mathrm{O} 2$-induced $\mathrm{PC} 12$ cell death via Nrf2/ARE activation. Bioorg Med Chem. 2010;18(9):3133-3139.

138. Hancock R, Bertrand HC, Tsujita T, et al. Peptide inhibitors of the Keap1-Nrf2 protein-protein interaction. Free Radic Biol Med. 2012;52(2):444-451.

139. Hancock R, Schaap M, Pfister H, Wells G. Peptide inhibitors of the Keap1-Nrf2 protein-protein interaction with improved binding and cellular activity. Org Biomol Chem. 2013;11(21):3553-3557.

140. Hirotsu Y, Katsuoka F, Itoh K, Yamamoto M. Nrf2 degron-fused reporter system: a new tool for specific evaluation of Nrf2 inducers. Genes Cells. 2011;16(4):406-415.

141. Kappos L, Gold R, Miller DH, et al. Effect of BG-12 on contrastenhancing lesions in patients with relapsing-remitting multiple sclerosis: subgroup analyses from the phase $2 \mathrm{~b}$ study. Mult Scler. 2012;18(3):314-321.

142. Gold R, Kappos L, Arnold DL, et al; DEFINE Study Investigators. Placebo-controlled phase 3 study of oral BG-12 for relapsing multiple sclerosis. N Engl J Med. 2012;367(12):1098-1107.

143. Bar-Or A, Gold R, Kappos L, et al. Clinical efficacy of BG-12 (dimethyl fumarate) in patients with relapsing-remitting multiple sclerosis: subgroup analyses of the DEFINE study. J Neurol. 2013;260(9):2297-2305.

144. Zoja C, Benigni A, Remuzzi G. The Nrf2 pathway in the progression of renal disease. Nephrol Dial Transplant. 2013. Epub June 11, 2013.

145. Hutchinson M, Fox RJ, Miller DH, et al. Clinical efficacy of BG-12 (dimethyl fumarate) in patients with relapsing-remitting multiple sclerosis: subgroup analyses of the CONFIRM study. J Neurol. 2013;260(9):2286-2296.

146. Lee DH, Stangel M, Gold R, Linker RA. The fumaric acid ester BG-12: a new option in MS therapy. Expert Rev Neurother. 2013;13(8):951-958.

147. Stangel M, Linker RA. Dimethyl fumarate (BG-12) for the treatment of multiple sclerosis. Expert Rev Clin Pharmacol. 2013;6(4):355-362.

148. Sheridan C. Third oral MS drug wins FDA nod. Nat Biotech. 2013;31(5):373.

149. Pollack A. 3rd oral drug to treat MS is approved by the FDA. NY Times. 2013;162(56089):B1-B12.

150. Herper M. Can biogen keep the party going after a flawless drug launch? Forbes.com. 2013:3

151. Pergola PE, Krauth M, Huff JW, et al. Effect of bardoxolone methyl on kidney function in patients with T2D and Stage 3b-4 CKD. Am J Nephrol. 2011;33(5):469-476.
152. Pergola PE, Raskin P, Toto RD, et al; BEAM Study Investigators. Bardoxolone methyl and kidney function in CKD with type 2 diabetes. N Engl J Med. 2011;365(4):327-336.

153. Reisman SA, Buckley DB, Tanaka Y, Klaassen CD. CDDO-Im protects from acetaminophen hepatotoxicity through induction of Nrf2-dependent genes. Toxicol Appl Pharmacol. 2009;236(1): 109-114.

154. Liby KT, Sporn MB. Synthetic oleanane triterpenoids: multifunctional drugs with a broad range of applications for prevention and treatment of chronic disease. Pharmacol Rev. 2012;64(4):972-1003.

155. Saito H. Toxico-pharmacological perspective of the Nrf2-Keap1 defense system against oxidative stress in kidney diseases. Biochem Pharmacol. 2013;85(7):865-872.

156. ClinicalTrials.Gov. Bardoxolone Methyl Evaluation in Patients With Chronic Kidney Disease and Type 2 Diabetes (BEACON). Available from: http://clinicaltrials.gov/show/NCT01351675. Accessed January 3, 2014. NCT identifier NCT01351675.

157. Zhang DD. Bardoxolone brings Nrf2-based therapies to light. Antioxid Redox Signal. 2013;19(5):517-518.

158. Zoja C, Corna D, Nava V, et al. Analogs of bardoxolone methyl worsen diabetic nephropathy in rats with additional adverse effects. Am J Physiol Renal Physiol. 2013;304(6):F808-F819.

159. Yore MM, Kettenbach AN, Sporn MB, Gerber SA, Liby KT. Proteomic analysis shows synthetic oleanane triterpenoid binds to mTOR. PLoS One. 2011;6(7):e22862.

160. Yeh LL, Liu JY, Lin KS, et al. A randomised placebo-controlled trial of a traditional Chinese herbal formula in the treatment of primary dysmenorrhoea. PLoS One. 2007;2(8):e719.

161. Chang PJ, Lin CC, Chen YC, et al. Use of herbal dietary supplement si-wu-tang and health-related quality of life in postpartum women: a population-based correlational study. Evid Based Complement Alternat Med. 2013;2013:790474.

162. Liu M, Fan J, Wang S, et al. Transcriptional profiling of Chinese medicinal formula Si-Wu-Tang on breast cancer cells reveals phytoestrogenic activity. BMC Complement Altern Med. 2013;13:11.

163. Zhan JY, Zheng KY, Zhu KY, et al. Importance of wine-treated Angelica Sinensis Radix in Si Wu Tang, a traditional herbal formula for treating women's ailments. Planta Med. 2013;79(7):533-537.

164. Hsu HY, Ho YH, Lin CC. Protection of mouse bone marrow by Si-WU-Tang against whole body irradiation. J Ethnopharmacol. 1996;52(2):113-117.

165. Liang QD, Gao Y, Tan HL, et al. Effects of four Si-Wu-Tang's constituents and their combination on irradiated mice. Biol Pharm Bull. 2006;29(7):1378-1382.

166. Evgen Pursues Pharmaceutical Development of Sulforadex. Nutraceuticals World. 2011;14(9):23.

167. Wang XJ, Hayes JD, Henderson CJ, Wolf CR. Identification of retinoic acid as an inhibitor of transcription factor Nrf2 through activation of retinoic acid receptor alpha. Proc Natl Acad Sci USA. 2007;104(49):19589-19594.

168. Wang H, Liu K, Geng M, et al. RXR $\alpha$ inhibits the NRF2-ARE signaling pathway through a direct interaction with the Neh7 domain of NRF2. Cancer Res. 2013;73(10):3097-3108.

169. Moon JH, Shin JS, Kim JB, et al. Protective effects of 6-hydroxy-1methylindole-3-acetonitrile on cisplatin-induced oxidative nephrotoxicity via Nrf2 inactivation. Food Chem Toxicol. 2013;62:159-166.

170. Lin CW, Wu MJ, Liu IY, Su JD, Yen JH. Neurotrophic and cytoprotective action of luteolin in PC12 cells through ERK-dependent induction of Nrf2-driven HO-1 expression. J Agric Food Chem. 2010;58(7):4477-4486.

171. Tang X, Wang H, Fan L, et al. Luteolin inhibits Nrf2 leading to negative regulation of the Nrf2/ARE pathway and sensitization of human lung carcinoma A549 cells to therapeutic drugs. Free Radic Biol Med. 2011;50(11):1599-1609.

172. Sun GB, Sun X, Wang M, et al. Oxidative stress suppression by luteolin-induced heme oxygenase-1 expression. Toxicol Appl Pharmacol. 2012;265(2):229-240. 
173. Zhang YC, Gan FF, Shelar SB, Ng KY, Chew EH. Antioxidant and Nrf2 inducing activities of luteolin, a flavonoid constituent in Ixeris sonchifolia Hance, provide neuroprotective effects against ischemia-induced cellular injury. Food Chem Toxicol. 2013;59: 272-280.

174. Liu R, Chen H, Bai H, et al. Suppression of nuclear factor erythroid 2-related factor 2 via extracellular signal-regulated kinase contributes to bleomycin-induced oxidative stress and fibrogenesis. Toxicol Lett. 2013;220(1):15-25

175. Viuda-Martos M, Ruiz-Navajas Y, Fernández-López J, PérezÁlvarez JA. Spices as functional foods. Crit Rev Food Sci Nutr. 2010;51(1):13-28.

176. Lee JH, Khor TO, Shu L, Su ZY, Fuentes F, Kong AN. Dietary phytochemicals and cancer prevention: Nrf2 signaling, epigenetics, and cell death mechanisms in blocking cancer initiation and progression. Pharmacol Ther. 2013;137(2):153-171.

177. Su ZY, Shu L, Khor TO, Lee JH, Fuentes F, Kong AN. A perspective on dietary phytochemicals and cancer chemoprevention: oxidative stress, nrf2, and epigenomics. Top Curr Chem. 2013;329: 133-162.

178. Cardozo LF, Pedruzzi LM, Stenvinkel P, et al. Nutritional strategies to modulate inflammation and oxidative stress pathways via activation of the master antioxidant switch Nrf2. Biochimie. 2013;95(8):1525-1533.

179. Boddupalli S, Mein JR, Lakkanna S, James DR. Induction of phase 2 antioxidant enzymes by broccoli sulforaphane: perspectives in maintaining the antioxidant activity of vitamins a, C, and e. Front Genet. 2012;3:7.

180. Kwak MK, Kensler TW. Targeting NRF2 signaling for cancer chemoprevention. Toxicol Appl Pharmacol. 2010;244(1):66-76.

181. James D, Devaraj S, Bellur P, Lakkanna S, Vicini J, Boddupalli S. Novel concepts of broccoli sulforaphanes and disease: induction of phase II antioxidant and detoxification enzymes by enhanced-glucoraphanin broccoli. Nutr Rev. 2012;70(11):654-665.

182. Wang R, Paul VJ, Luesch H. Seaweed extracts and unsaturated fatty acid constituents from the green alga Ulva lactuca as activators of the cytoprotective Nrf2-ARE pathway. Free Radic Biol Med. 2013;57:141-153.

183. Heber D, Li Z, Garcia-Lloret M, et al. Sulforaphane-rich broccoli sprout extract attenuates nasal allergic response to diesel exhaust particles. Food Funct. 2013;5(1):35-41.

184. Kropat C, Mueller D, Boettler U, et al. Modulation of Nrf2-dependent gene transcription by bilberry anthocyanins in vivo. Mol Nutr Food Res. 2013;57(3):545-550.

185. Wu TY, Khor TO, Lee JH, et al. Pharmacogenetics, pharmacogenomics and epigenetics of Nrf2-regulated xenobiotic-metabolizing enzymes and transporters by dietary phytochemical and cancer chemoprevention. Curr Drug Metab. 2013;14(6):688-694.

186. Reuland DJ, Khademi S, Castle CJ, et al. Upregulation of phase II enzymes through phytochemical activation of Nrf2 protects cardiomyocytes against oxidant stress. Free Radic Biol Med. 2013;56:102-111.

187. Murakami A, Ohnishi K. Target molecules of food phytochemicals: food science bound for the next dimension. Food Funct. 2012;3(5):462-476.

188. Niture SK, Khatri R, Jaiswal AK. Regulation of Nrf2-an update. Free Radic Biol Med. Epub February 19, 2013.

189. Giudice A, Montella M. Activation of the Nrf2-ARE signaling pathway: a promising strategy in cancer prevention. Bioessays. 2006;28(2):169-181.

190. Surh YJ, Kundu JK, Na HK. Nrf2 as a master redox switch in turning on the cellular signaling involved in the induction of cytoprotective genes by some chemopreventive phytochemicals. Planta Med. 2008;74(13):1526-1539.
191. Velmurugan K, Alam J, McCord JM, Pugazhenthi S. Synergistic induction of heme oxygenase-1 by the components of the antioxidan supplement Protandim. Free Radic Biol Med. 2009;46(3):430-440.

192. Lisk C, McCord J, Bose S, et al. Nrf2 activation: A potential strategy for the prevention of acute mountain sickness. Free Radic Biol Med. 2013;63:264-273.

193. Nelson SK, Bose SK, Grunwald GK, Myhill P, McCord JM. The induction of human superoxide dismutase and catalase in vivo: a fundamentally new approach to antioxidant therapy. Free Radic Biol Med. 2006;40(2):341-347.

194. Liu J, Gu X, Robbins D, et al. Protandim, a fundamentally new antioxidant approach in chemoprevention using mouse two-stage skin carcinogenesis as a model. PLoS One. 2009;4(4):e5284.

195. Qureshi MM, McClure WC, Arevalo NL, et al. The dietary supplement protandim decreases plasma osteopontin and improves markers of oxidative stress in muscular dystrophy mdx mice. J Diet Suppl. 2010;7(2):159-178.

196. Robbins D, Gu X, Shi R, et al. The chemopreventive effects of Protandim: modulation of p53 mitochondrial translocation and apoptosis during skin carcinogenesis. PLoS One. 2010;5(7):e11902.

197. Joddar B, Reen RK, Firstenberg MS, et al. Protandim attenuates intimal hyperplasia in human saphenous veins cultured ex vivo via a catalasedependent pathway. Free Radic Biol Med. 2011;50(6):700-709.

198. Burnham EL, McCord JM, Bose S, et al. Protandim does not influence alveolar epithelial permeability or intrapulmonary oxidative stress in human subjects with alcohol use disorders. Am J Physiol Lung Cell Mol Physiol. 2012;302(7):L688-L699.

199. Donovan EL, McCord JM, Reuland DJ, Miller BF, Hamilton KL. Phytochemical activation of Nrf2 protects human coronary artery endothelial cells against an oxidative challenge. Oxid Med Cell Longev. 2012;2012:132931.

200. Reuland DJ, McCord JM, Hamilton KL. The role of nrf2 in the attenuation of cardiovascular disease. Exerc Sport Sci Rev. 2013;41(3):162-168

201. Wang XJ, Hayes JD, Wolf CR. Generation of a stable antioxidant response element-driven reporter gene cell line and its use to show redox-dependent activation of nrf2 by cancer chemotherapeutic agents. Cancer Res. 2006;66(22):10983-10994.

202. Gounder SS, Kannan S, Devadoss D, et al. Impaired transcriptional activity of Nrf2 in age-related myocardial oxidative stress is reversible by moderate exercise training. PLoS One. 2012;7(9):e45697.

203. Miller CJ, Gounder SS, Kannan S, et al. Disruption of Nrf2/ARE signaling impairs antioxidant mechanisms and promotes cell degradation pathways in aged skeletal muscle. Biochim Biophys Acta. 2012;1822(6):1038-1050.

204. Muthusamy VR, Kannan S, Sadhaasivam K, et al. Acute exercise stress activates Nrf2/ARE signaling and promotes antioxidant mechanisms in the myocardium. Free Radic Biol Med. 2012;52(2):366-376.

205. Zhao X, Bian Y, Sun Y, et al. Effects of moderate exercise over different phases on age-related physiological dysfunction in testes of SAMP8 mice. Exp Gerontol. 2013;48(9):869-880.

206. Lewis KN, Mele J, Hayes JD, Buffenstein R. Nrf2, a guardian of healthspan and gatekeeper of species longevity. Integr Comp Biol. 2010;50(5):829-843.

207. Lee JM, Calkins MJ, Chan K, Kan YW, Johnson JA. Identification of the NF-E2-related factor-2-dependent genes conferring protection against oxidative stress in primary cortical astrocytes using oligonucleotide microarray analysis. J Biol Chem. 2003;278(14):12029-12038.

208. Jiang T, Huang Z, Lin Y, Zhang Z, Fang D, Zhang DD. The protective role of Nrf2 in streptozotocin-induced diabetic nephropathy. Diabetes. 2010;59(4):850-860. 


\section{Publish your work in this journal}

Clinical Pharmacology: Advances and Applications is an international, Visit http://www.dovepress.com/testimonials.php to read real quotes peer-reviewed, open access journal publishing original research, reports,

reviews and commentaries on all areas of drug experience in humans.

The manuscript management system is completely online and includes

a very quick and fair peer-review system, which is all easy to use.

from published authors.

Submit your manuscript here: http://www.dovepress.com/clinical-pharmacology-advances-and-applications-journal 